\title{
Memorias del Subsuelo: Exploración de la Economía de los Valores en el Chile Actual ALBERTO MAYOL MIRANDA ${ }^{1}$
}

\begin{abstract}
Resumen
Este artículo constituye un esfuerzo por dar cuenta de las articulaciones valorativas que se actualizan y reproducen en las interpretaciones que los actores sociales realizan sobre la realidad pública chilena actual. Se trata de observar aquellos valores que, aun teniendo un fuerte contenido político, son menos una 'cultura política' que un trasfondo normativo que articula las voluntades de construcción del destino político común. Son los valores de la polis más que de la política. En este sentido, la comprensión del sitio y el significado de ciertos valores públicos fundamentales, como el orden, la igualdad, la libertad, la justicia y el progreso; el esfuerzo por describir las relaciones entre realidades materiales y construcciones valorativas; la descripción de las características culturales más sólidas y fértiles en la vida simbólica chilena; constituyen los desafios que se han afrontado en este documento, que muestra una conservación del orden vacía de sentido, una fractura significativa en los imaginarios de orden social entre los ricos y el resto; además de un conjunto de transformaciones incipientes asociadas al predominio del consumo y el emprendimiento como formas integrativas predominantes en el Chile actual.
\end{abstract}

PALABRAS CLAVE: Valores, Sociología de la Cultura, Cultura Política, Chile

\begin{abstract}
This article is an effort to state the value articulations which are upgrated and reproduced in the interpretations made by social forces on the current public Chilean reality. We will examine those values which, thus with less strong political content, are less a "political culture" than a normative background that articulate the will of a common political destiny. They are more values of the polis than of politics. In this sence, the comprehension of the site and the meaning of certain public fundamental values, like order, equalness, freedom, justice and progress; the effort to describe the relations between material realities and value constructions; the description of the most solid and fertil cultural characteristics in the Chilean symbolic life; they form the challenges that have been confronted in this document, which show a conservation of order out of sence, a significant fracture in the imaginaries of social order between the rich and the rest; besides a group of incipient transformations associated to the realm of consumption and enterpreneuring as predominating integrative for$\mathrm{ms}$ in Chile nowadays.
\end{abstract}

KEYWORDS: values, culture sociology, political culture, Chile.

Profesor del Departamento de Sociología de la Universidad de Chile. Investigador del Centro de Investigación en Estructura Social (CIES) de la Universidad de Chile en el marco de la Iniciativa Científica Milenio. Director de estudios convenio Expert S.A. y Centro de Estudios Sociales y Políticos (CESPOL). 
Revista de Sociolocía 21 / 2007 Chile Hoy

Facultad de Ciencias Sociales - Universidad de Chile

\section{1) Discusiones Culturales sobre el Chile Contemporáneo}

Las discusiones sobre el estado de la cultura en Chile han sido abundantes. A veces fértiles. El informe del PNUD del año 1998, referido a las paradojas de la modernización, puso el malestar en la cultura en el primer plano sociológico, realizando así un redescubrimiento altamente significativo: el de la jaula de hierro. Hay quienes han visto la tensión entre avance del capitalismo, modernización, marcos normativos y subjetividad como la cuestión de fondo de lo que suele conocerse como 'crisis en los valores' (Cortés, 2001). Esta tensión es la que se presenta ante el cuestionamiento de los valores ‘tradicionales' en las prácticas cotidianas, respecto a la fortaleza de esos mismos valores en los ideales de sociedad; que a su vez se confronta con los mensajes 'globalizados' que portan mensajes culturales 'no tradicionales' y que se aparecen como otro ideal normativo (Lahera, s/f). De hecho, las tensiones manifiestas por los conservadores sobre la crisis en la familia chilena suelen relacionarse tanto con las transformaciones conductuales, como con la influencia de formas ideales de construcción de familia que se aprecian en "el modelo de familia anglosajón (que) ha sido difundido planetariamente" (Finol, 2006), tensiones que por cierto suelen relacionarse con el tipo de sociedad que políticamente los grupos que acusan de crisis moral están promoviendo desde otros puntos de vista (el económico por ejemplo). Por cierto, en los últimos años hemos visto diversos debates que han sido abordados como manifestaciones de la crisis valórica ${ }^{2}$ o moral del país, fundamentalmente en los temas asociados a las decisiones sobre conducta sexual, marcos jurídicos de la vida familiar y salud reproductiva ${ }^{3}$. Esos debates no han llegado a constituirse en cuestiones 2 Por algún motivo, el neologismo 'valórico' o 'valórica' se utiliza con frecuencia en el lenguaje técnico y coloquial en Chile con ocasión de estas discusiones. Por supuesto, los términos 'valorativo' o 'valorativa' satisfacen mejor el criterio de comprensión universal que los conceptos pretenden.

3 La 'agenda valórica' -como le llaman los medios- expresa las discusiones sobre el divorcio, el aborto terapéutico, el anticonceptivo de emergencia, las uniones civiles homosexuales y otros temas que generan una fuerte división en Chile. Las instituciones defensoras de valores tradicionales han sostenido estas temáticas como núcleo de su acción pública. Por ejemplo, en el Te Deum del 18 de septiembre de 2006, evento ecuménico que se realiza en el marco de la festividad republicana que conmemora el inicio del proceso de independencia de Chile en el 1810; Monseñor Francisco Javier Errázuriz dio cuenta de un estado de crisis moral en nuestra sociedad. Al respecto señaló: "son muchos los chilenos que (...) se sienten desconcertados. Constatan que es difícil discernir, cuando nuestra vida transcurre en medio de grandes cambios. Es más, se discute acerca de la naturaleza del amor, del matrimonio y la familia, pilares de toda sociedad, y acerca de la función del Estado en estos ámbitos vitales. Esta situación implica un formidable desafio. Justamente al prepararnos a la celebración del bicentenario de nuestra Patria debemos hacer un discernimiento profundo de cuanto surge y de cuanto se marchita, de cuanto es signo de salud o de enfermedad, de lo que se quiere alterar o defender, de cuanto se propone y es flor de un día, y de lo que echa raíces y se fortalece. Hay que hacerlo (...) en diálogo con quienes intentan globalizar sus proyectos y cosmovisiones, pero sin permitir que nos colonicen ni avasallen, y con la dignidad y la gratitud propias de un pueblo que tiene conciencia de los dones recibidos de Dios".

"Junto con agradecerle a Dios el modelo de familia que nos confió, queremos seguir formando personalidades, esposas y esposos que hagan suyo el mandamiento nuevo, es decir, que pongan todo su esfuerzo y su alegría en amarse como Cristo nos amó". http://www.emol.com/noticias/documentos/pdfs/tedeum2006.pdf

Pero esta mirada ha encontrado actores sociales crecientemente dispuestos a disputar la interpretación de la realidad con nuevos marcos normativos. De mucho interés resulta el caso de la discusión del anticonceptivo de emergencia o píldora del día después, donde un médico de la misma Universidad Católica fue finalmente despedido de esa universidad por señalar los resultados e de sus investigaciones que revelaban la píldora como no abortiva. En ese debate, el médico (Horacio Croxatto) llegó a expresar su impresión de que la Iglesia cumplía un rol deliberado de desinforma- 
Memorias del Subsuelo: Exploración de la Economía de los Valores en el Chile Actual / Alberto Mayol Miranda

sociológicas de primer orden, aun cuando el mercado de encuestas lo ha convertido en un tema permanente.

De cualquier modo, la cuestión cultural ha supuesto cierta atención significativa. Por ejemplo, en la obra consular de la sociología chilena de los noventa, "Chile Actual: Anatomía de un Mito", Tomás Moulian dio cuenta de las presiones estructurales que ha supuesto la conversión de la economía de libre mercado como un telos inevitable. En ese contexto los marcos normativos se han dirigido a la legitimación del ideal social de la ganancia económica como modo predominante de prestigio, ejerciendo entonces una presión valorativa el imaginario de la abundancia (Moulian, 2002: 135 y ss) como medio de salvación predominante. Desde una problematización cercana a ésta, una de las tematizaciones recurrentes ha sido la búsqueda de una comprensión de las relaciones entre desarrollo y cultura. Esta problemática abunda, no sólo en Chile, en el intento por comprender cómo aportan ciertos rasgos culturales al desarrollo y cómo influye el desarrollo en la generación de transformaciones culturales ${ }^{4}$. Las visiones sobre estas relaciones van desde la crítica a la noción misma de desarrollo como imperialismo cultural hasta la asimilación de las lógicas del mercado como forma de selección óptima de los valores (Valenzuela, 2005).

En este artículo asumimos esta historia de problematizaciones. Sin embargo, la pretensión es concentrar la atención en aquellas características culturales que pudieran estar sustentando estas discusiones, el trasfondo. Es posible - en nuestros tiempos- que lo sólido se desvanezca en el aire, pero por motivos metodológicos nos concentraremos precisamente en lo sólido o sus residuos y no en los desvanecimientos. Por eso, es de interés comprender el conjunto de valores que se encuentran encarnados e incorporados, esos que son salvaguardados por instituciones, normas, leyes y contratos. Pero, sobre todo, se intenta comprender la articulación de valores que en su carácter dominante tiene la garantía más relevante: la cotidianeidad. Se trata de comprender la configuración valorativa de la polis, esto es, ese cuerpo de valores que se hallan en un nivel geológicamente más profundo y que de algún modo constituyen determina-

ción. En entrevista en Página 12 de Buenos Aires, el año 2002, señaló:

"(La estrategia de desinformar y mentir es) absolutamente deliberada. En Chile, de donde puedo hablar con bastante conocimiento, los médicos que empezaron a hablar en contra de la anticoncepción de emergencia son personas que jamás en su vida han trabajado en el tema y de la noche a la mañana se constituyeron en expertos (...). Dijeron cualquier cantidad de barbaridades y es gente que viene de universidades católicas o del Opus Dei. Esas son sus banderas de lucha porque la católica es una religión sexofóbica: usted piense que la virgen María tuvo que ser virgen para tener al hijo de Dios, los sacerdotes tienen que ser célibes, en fin" http://www.pagina12.com.ar/diario/sociedad/3-129662002-11-17.html

Esta tensión y la consiguiente presencia de una 'agenda valórica' constituyen signos claros de una disputa por los valores predominantes en los próximos años en medio de una disputa que incorpora fuerte presencia de valores tradicionales, una presencia relativamente consolidada de algunos valores modernos (aunque crecientemente cuestionados), a lo que se suma la existencia de valores postmodernos.

$4 \quad \mathrm{Al}$ respecto, Inglehart - por ejemplo- está convencido de que "el desarrollo económico y los cambios culturales y políticos están vinculados de manera coherente, e incluso, hasta cierto punto, siguiendo modelos predecibles" (Inglehart, 1994: 65). 
ciones para las manifestaciones cotidianas de las regularidades subyacentes. Esta labor es por supuesto imposible de satisfacer en este modesto artículo y dadas las homólogas capacidades del autor. Por tanto, como se dice en estos casos en la comunidad científica, se trata simplemente de aportar algunas observaciones a un programa de investigación mucho más amplio.

La pregunta por la encarnación de los valores en una sociedad concreta (en nuestro caso Chile) supone un conjunto de inconvenientes en las dimensiones teóricas, metodológicas y analíticas. Llegar a conocer los valores preeminentes, a bosquejar las posibles condiciones por las que han llegado a ser valores superiores de la polis, a comprender los entronques con determinados intereses y a barruntar las afinidades electivas que contingentemente le están asociadas; constituye un desafío que -sin pretender ostentar dificultades excesivas- resulta al menos complejo.Y no lo es tanto porque el caso chileno tenga particularidades que dificulten la mirada. Ocurre que la investigación y el análisis de los valores suponen tensiones en la polaridad racionalidad/irracionalidad que complejizan su tratamiento.

Sin pretender abundar en la teoría, es necesario señalar que la reflexión weberiana de una racionalidad en la acción con arreglo a valores nos muestra que el carácter racional de este tipo de acción no está determinado por una característica esencial de los valores (ya que no son racionales), sino por la posibilidad de racionalización que los valores poseen: los valores son jerarquizables y sistematizables. La 'ordenación transitiva de los valores', esto es, la posibilidad de poner a los valores unos después de otros, es la forma fundamental que adquiere la racionalidad en el mundo de los valores. Sin embargo, los valores son constructos fuertemente influidos por la dimensión afectiva, al tiempo que están constreñidos por la vida normativa, tensionados por los intereses, manipulados por los poderes, adheridos a las matrices de percepción y releídos permanentemente por los receptores. Su grado de racionalidad es entonces muy bajo y sólo adquiere ese atributo en la medida en que los valores se articulan y configuran un sistema de valores, en lo posible normativamente garantizado, momento en el cual la capacidad de actuar en un escenario de control y predicción aumenta. Los valores, entonces, son un fenómeno que cruza las formas más irracionalizadas y las más racionalizadas de la vida social. Transitamos, con ellos, la tortuosa ruta que hay entre la convicción de valores fundamentados (razón, fe) hasta el entronque poder-valor y sus oscuros parajes. Es la 'tensión Dostoyevski'.

A todo esto se debe sumar una dificultad añadida y es que los valores no pueden ser completamente diferenciados de las normas sociales (Sorokin, 1969) y que, sin embargo, es imprescindible hacerlo (Piaget, 1983). De hecho, esta dualidad valoresnormas es decisiva para comprender las tendencias a la estabilización o la desestabilización de los valores. En un análisis teórico brillante sobre los valores, Piaget da 


\section{Memorias del Subsuelo: Exploración de la Economía de los Valores en el Chile Actual / Alberto Mayol Miranda}

cuenta de la enorme inestabilidad de los equilibrios valorativos. "Por eso, además de los mecanismos de intercambio, toda sociedad presenta un conjunto de operaciones generales (casi se podría decir de dispositivos) de conservación de los valores" (Piaget 1983: 138). Y es así como sociológicamente son las normas las que se constituyen como "operaciones que tienden a la conservación de los valores en los intercambios" (Piaget, 1983: 140). Entonces, los marcos valorativos pueden estar anclados fuertemente en dispositivos normativos y, por tanto, caracterizarse por su estabilidad; o pueden estar desvinculados de entronques con normas, caracterizándose así por su fluidez e inestabilidad. La relación, entonces, entre los actores sociales y los valores depende de las objetivaciones que estos han conseguido y de las lógicas de intercambio que sean posibles y probables en un determinado estado de los valores. A este respecto, el puro descriptivismo de los valores conduce a la sociología a conclusiones insuficientes. Es necesario comprender las condiciones de su reproductibilidad.

Para comprender la relación de los actores con los valores y cómo esta relación genera consecuencias al nivel del orden social, debemos estar dispuestos a asumir la plasticidad del fenómeno y sus manifestaciones. Hay quienes, como Kluckhon (1951), vislumbraron una economía de los valores en tanto no se pueden tomar todas las decisiones posibles. En esa opción, bajo la lógica del recurso escaso, el actor se inserta en un proceso de selección que puede ser entendido como una economía. Hay quienes, en cambio, ven la economía de los valores como todos los estudios de transmutación de los valores y que además asumen como necesidad el hecho de que esta problemática sea vista a la manera de una economía política (Baudrillard, 1991). En esta ocasión se prefiere asumir una economía de los valores en un sentido distinto, aunque evidentemente cercano de alguna manera a ambas miradas. Cada valor, puesto en un sitio determinado, supone un conjunto finito y hasta restrictivo de posibilidades de movimiento de los actores y sus intereses. La economía de los valores no sólo debe referir a la manera en que se pueden ordenar, elegir o transformar los valores: es la constitución de un espacio de atributos económicos en los que se producen, circulan, se apropian, se negocian y se excluyen determinados valores. Son las reglas del intercambio, las formas en que se expresa la capacidad de los valores para constituirse a la manera de un valor de cambio frente a otros valores, sistemas de valores o frente a la realidad que amerita ser evaluada, juzgada.

Esta visión económica de los valores es, al menos en este instante, un instrumento metodológico y no pretende señalar nada sobre la ontología de los valores. Esto pues no es la pretensión de este documento aproximarnos teóricamente al problema de los valores ${ }^{5}$. El esfuerzo que aquí se plasma radica estrictamente en el intento por comprender mejor la dimensión valorativa en el Chile actual.Y, por supuesto, no se trata de dar cuenta de todos los valores. Se trata de concentrarnos en la producción $5 \quad$ El trabajo teórico respecto a los valores se ha realizado en la investigación doctoral del autor (el uso del término 'realizar' no refiere al grado de éxito de dicha investigación). 
y reproducción de valores propios de la construcción de sentido político (en tanto sentido de la polis) en el Chile actual. Esos valores son los que constituyen la matriz orientativa del orden social, su espíritu. No se trata de apreciar los valores de los políticos, ni los valores de la esfera política o sistema político. No se trata, tampoco, de comprender los valores declarados por los actores relevantes ni por la ciudadanía y sus modestos alcances. De lo que se trata es de comprender el régimen de valores socialmente instalados para efectos de la vida pública, esto es, aquellos valores con eficacia política, que responden a los intereses, que sustentan el orden (o que pueden transformarlo), que son susceptibles de uso ideológico, que se tornan marcos de sentido para interpretar la realidad y que, en definitiva, se constituyen como el espacio simbólico de los valores legítimos en Chile. Hablamos en el título de una memoria del subsuelo por dos motivos: porque los valores tienden a estar situados en la esfera de lo aproblemático. Son orientadores, por lo que su discusión es en cierto sentido de última instancia. Se actualizan cada día sobre la tierra, pero sus tiempos están en la geología del subsuelo. Pero hay una segunda razón. La sublime obra de Dostoievski "Memorias del Subsuelo" es la cruda reflexión de un sujeto sobre sí mismo. Algo de esta visión descarnada se hace imprescindible. Este artículo es modesto en el esfuerzo. Falta material, pero ante todo osadía. Sin embargo, la invitación está cursada.

El presente es un esfuerzo por abordar los signos (o síntomas) de una cultura en un momento determinado (un momento en sentido amplio, una serie de latidos que permitan dar cuenta de las regularidades). Más que conocer todos los valores, se trata de concentrar la mirada en algunos de ellos, desplegados por su importancia, intentando conocer de ellos su sitio exacto en la articulación de valores dominante. Metodológicamente se hará uso de una cantidad de información importante, recopilada a partir de diversas investigaciones empíricas con énfasis culturalista, realizadas desde el año 2002 a la fecha (diciembre de 2007) y que se harán dialogar con una literatura que ha realizado algunas observaciones que otorgan fuerza explicativa a las descripciones aquí provistas. Los antecedentes recopilados provienen de estudios tanto cualitativos como cuantitativos. Han supuesto un trabajo interpretativo intenso y plantean un problema de validación sustantivo, debido a que son retazos, fragmentos de diversos estudios. Muchos de ellos provienen de demandas privadas, lo que suele llamarse estudios de mercado ${ }^{6}$. Sin embargo, en el collage de informaciones recopiladas destaca el nivel de saturación (esto es, la asfixiante recurrencia) de un conjunto de valores y articulaciones valorativas que parecen constituirse en el espíritu que vivifica (o mortifica) nuestra época ${ }^{7}$. En ellos se concentrará esta mirada.

6 No todos los estudios tenían por fin clientes privados de corte empresarial. Muchos de los estudios realizados eran estudios orientados a conocer situaciones políticas determinadas, ya sea con fines privados o con fines publicitarios de la consultora que los realizaba. En cualquiera de los casos -en lo que constituye un rasgo de por sí sorprendente- siempre los clientes políticos llaman 'estudios de mercado' a las investigaciones. Este es un dato en sí mismo que merece cierta atención. Los políticos dicen necesitar 'estudios de mercado', entendiendo su elección desde una perspectiva particularmente restringida. No es hora de sacar conclusiones sobre esto, sin embargo, es tiempo de observarlo.

7 Es un implícito importante señalar que el "Chile Hoy" parece hacer sentido en tanto la realidad post-dicta- 
Memorias del Subsuelo: Exploración de la Economía de los Valores en el Chile Actual / Alberto Mayol Miranda

\section{2) Las Huellas de la Vida Política Chilena}

La vida simbólica de la política chilena ha estado marcada por significantes cargados al punto del superávit de sentido: //Allende//, //golpe//, //Pinochet//, //militares//, //dictadura//, //No//,//transición//, //modelo//, //democracia//, //neoliberales//, //consenso//, //Concertación//, entre otros términos de recurrencia evidente. Los avatares simbólicos de estos términos han sido analizados por diversos especialistas en los últimos años. Joignant, Moulian, Thayer y Richards, por nombrar algunos ejemplos, se han involucrado -con muy distintos enfoques y resultados- en la observación de estos cruces entre lo social, lo cultural y lo político ${ }^{8}$. De cualquier modo, lo normal es y ha sido que el análisis político y social tenga su especificidad, dentro de la cual una breve referencia a la cultura resulta funcional a un análisis que finalmente la omite. Todo esto bajo la premisa de las cuestiones culturales o son cuestiones relacionadas -exclusivamente- al consumo de bienes culturales, o que son problemas que se deben analizar en términos de déficit de cultura que explicaría (o sería resultante de) nuestro subdesarrollo, o sencillamente bajo la idea de que la cultura se limita a problemáticas del mundo de la educación, del arte o de ciertas instituciones en concreto. En definitiva, la tendencia en el debate de las ciencias sociales ha sido tratar la cultura como una variable o un conjunto de ellas.Y sin embargo, la cultura carece de los requisitos para ser tratada a la manera de una variable. Es cierto que la cultura varía si observamos distintos lugares, lo que la convertiría en variable. $\mathrm{Y}$ es cierto que bajo ninguna circunstancia podría ser el opuesto a una variable, esto es, una constante. Pero el inconveniente es que la noción de variación del concepto de variable es unidimensional, pues de otro modo pierde capacidad explicativa.Y la cultura es plástica. No varía en el sentido restringido, muta en el sentido amplio. Una variable es una modificación de puntos en un espacio. La cultura y sus mutaciones son las modificaciones de los espacios mismos donde ubicar los puntos.

Es así como suele ocurrir que la mirada sobre la cultura tiende a configurarse como una reificación de una esfera cultural al punto de su conversión en un paquete, un espacio demarcado, limitado, definido, instalado. Los análisis con sensibilidad culturalista que han sido mencionados tienden a no dejarse llevar por estas miradas. Sin embargo, los implícitos analíticos del grueso de nuestras ciencias sociales tienden a operar con una versión muy poco plástica (muy poco ágil) del famoso esquema parsoniano, conocido como AGIL precisamente por la referencia a un esquema dúctil, que claramente hoy se transformado en un petrificado supuesto.

torial. En este artículo hay cierto énfasis en el Chile del siglo XXI, pero no es menos cierto que se asumen numerosos antecedentes anteriores.

8 Las ciencias sociales deben poner atención, de todos modos, al interesante esfuerzo sobre los entronques sociales, políticos y culturales que se están realizando en las investigaciones históricas que en forma multiplicativa han ido emergiendo en Chile. La constitución creciente de debates en la historiografia, la presencia de diferencias epistémicos, los riesgos interpretativos, hablan de una fertilidad interesante en ese ámbito. 
En definitiva, no es posible diferenciar la cultura en tanto cultura política o imaginarios sobre la sociedad. La cultura interpreta la realidad a partir de formas simbólicas cuya definición de límites es siempre difusa. La traza de límites es arbitraria, analítica como diría el mismo Parsons, pero la realidad cultural supone una mirada astigmática. Por ello, este artículo pretende insertarse en el esfuerzo de multiplicar las interpretaciones sobre la 'cultura' en el Chile actual, caracterizable en la simbólica política por ser el Chile post-Pinochet, a su vez que definible por la consolidación de la economía de mercado en términos de modelo económico y sintomatizado por la idea de transición a la democracia como residuo o deuda de la historia reciente ${ }^{9}$. En este marco, la pretensión ha sido ordenar un conjunto de resultados empíricos -cualitativos y cuantitativos- que han sido recopilados en los últimos años, otorgándoles el estatus de fragmentos cuyas pulsaciones pueden permitirnos el armado de una totalidad que, sin dejar de ser una simple reconstrucción, permita un incremento en el potencial explicativo y descriptivo de los movimientos de nuestra cultura.

Sin recurrir aún al material empírico, la literatura culturalista es explícita en señalar el espíritu transformador del golpe de 1973, su pretensión refundacional. Como señala W. Thayer "La declaración policial-militar del estado de excepción en 197380 (...) tendrá, lo sabemos ahora, desde hace tiempo, desde 1980 por lo menos, un carácter eminentemente fundacional (...) Se trató del ejercicio de la Dictadura soberana que declara el estado de excepción con la finalidad de refundar el derecho" (Thayer, 2006: 77 y 78). En este sentido, la declaración de 1974 de la Junta de Gobierno se considera un documento de evidente sentido fundacional (Moulian, 2002), por lo demás exitoso en la conquista del grueso de los objetivos (véase Mayol, 2007: 103).

A veces se confunde la pretensión refundacional de la dictadura con la noción de proyecto, pues se instala la convicción de que el fin (refundar) supone la existencia de un proyecto claramente definido. Pues bien, indudablemente eso es un error. Puede haber existido el proyecto (la declaración de 1974 de algún modo muestra algo parecido al proyecto), pero la pretensión refundacional opera en un nivel diferente: es ante todo una interpretación del malestar. El golpe instala la idea de que las formas del malestar existente requerían una transformación violenta y

9 La cuestión de la transición merece un tratamiento específico para el que este artículo no constituye el espacio óptimo. Es evidente que la resolución de la transición no se ha producido en los términos del ideal politológico dictadura-transición-democracia. El fin del debate de la transición no se presenta como correlato de la garantía democrática, sino como resultado del mero desgaste de su sentido histórico, incluso como falsación de la tesis politológica. Esto es, en la medida en que no hay nada después de la transición, que ella no es medio, entonces la transición permanente tiene que 'transitar' hacia nuevas denominaciones. 'Chile Post-Pinochet' es la más afortunada, porque da cuenta del momento de la 'transición sin dictador'. Sin embargo, lo normal es que para este período ya no exista ni siquiera un nombre. De algún modo, abusando del afán descriptivista, es el momento de la consolidación de la transición. 
Memorias del Subsuelo: Exploración de la Economía de los Valores en el Chile Actual / Alberto Mayol Miranda

radical. Eso fundamenta el espíritu transformador de la 'dictadura', que tiene su gran mérito en la articulación de las formas del malestar existentes en su origen a la manera de una necesidad de proyecto histórico de corte refundacional. Por eso, culturalmente no es importante que el proyecto ya existiera ${ }^{10}$, sino que es relevante la percepción de requerirlo para la construcción del Chile futuro. La nueva Constitución, la Reforma Educacional, el Ajuste Estructural, el nuevo Sistema de Pensiones, entre otras transformaciones, encuentran su alimento no sólo en la violencia, pues ella es eficaz mientras la legitimidad no baje de cierto umbral. Por eso, incluso más allá del apoyo a Pinochet, que lo tenía en niveles interesantes, lo importante es que incluso entre quienes lo rechazaban estaban presentes condiciones de legitimación ${ }^{11}$ de sus actos. La dictadura de la Junta de Gobierno y Pinochet es exitosa allí donde es más dificil: proyectar el fin del malestar como una conquista posible y dejar instalado el mensaje de que los excesos de derechos del pasado podían estar pasando una cuenta (generándose una deuda con el orden). Porque son muchos en la historia los que pueden interpretar en un momento el malestar de un grupo humano.Y es posible que articulen esa sintonía a la manera de una oposición y hasta de una transformación. Pero lograr transmutar el malestar objetivado en un 'otro', en un proyecto de futuro propio, no es algo frecuente en la historia. Y Pinochet lo logró.

Sin ir más lejos, he aquí un desafio pendiente en la Concertación, que ya quedó sin resolver. El triunfo del 'No' es exactamente eso, el triunfo de la palabra ("No") que representó una nueva forma de malestar. Las restricciones de la libertad ya no eran toleradas. Esto no significa que la derrota de Pinochet es culturalista: hay razones internacionales, económicas y de política interna dura. Pero indudablemente el malestar se hacía masivo. Las formas tibias de insurrección, como las cacerolas sonando, los estudiantes botando a Federici ${ }^{12}$, son señales inequívocas del fin del efecto del miedo, del esfuerzo por dar a conocer anónimamente el apoyo necesario para señalar que el fin de la dictadura estaba por venir. Sin embargo, el campo semántico del triunfo del No fue muy restringido. Sólo ganó el No. La percepción de que ganó la democracia o que ganó la gente nunca tuvo eficacia social. Fue un 10 Indudablemente el famoso convenio de la Universidad Católica con la Universidad de Chicago ya tenía casi veinte años y suponía un proyecto (conocido como neoliberal) que compitiera con los proyectos instalados e incluso operativos en Chile.

11 La referencia a condiciones de legitimación puede inducir a confusiones. No se trata de la noción mecánica de la legitimidad como aceptación de la dominación en un sentido directo. Hay formas perversas o desviadas de legitimación: la sensación de culpa, de que el Golpe es obra de todos y no sólo de los que lo ejecutan, es una evidente condición de legitimación, pues traslada la esfera de la explicación externa del evento Golpe de Estado a una responsabilidad moral respecto a las condiciones de control del contexto. No pretende emitir un juicio sobre esta forma de legitimación. Sólo refiero al hecho que aparece como indesmentible: hay posiciones, argumentos, emociones que legitiman el Golpe sin necesidad de que el actor lo apoye y de hecho rechazándolo.

12 En 1987 los estudiantes de la Universidad de Chile, principal universidad pública del país e intervenida en la dictadura, lograron derrocar al rector de turno, José Luis Federici, en un movimiento que fue tomado como señal de que el fin del gobierno autoritario estaba por venir, ya que demostró la incapacidad de Pinochet de imponer su voluntad en un espacio organizacional políticamente decisivo como es la Universidad de Chile. 
campo semántico empobrecido el que generó que la única figura consular fuera Pinochet. Los demás eran simples antípodas. La construcción de la democracia se hizo pensando en ser diferente a Pinochet, no pensando en las democracias. Todo fue reemplazar la figura del dictador. Se trató de reescribirlo todo: la Constitución firmada por Lagos en reemplazo de Pinochet fue el símbolo contundente de esa lógica.

La transición, el modelo, la democracia, esto es, toda referencia a un proyecto -aunque fuese incipiente- entraron en la tibia habitación del consenso, lo que no era más que decir: siempre preguntaremos antes de hacer, siempre intentaremos saber si se enojan, no queremos llevar al distanciamiento que antes costó violencia. La fiebre del consenso había llegado: todo estaba en ponerse de acuerdo. Como señala Nelly Richards:

“La democracia de los acuerdos (...) señaló el paso de la política como antagonismo (...) a la política como transacción: la fórmula del pacto y su tecnicismo de la negociación. La 'democracia de los acuerdos' hizo del consenso su garantía normativa, su clave operacional, su ideología desideologizante, su rito institucional, su trofeo discursivo (Richards, 2007:133).

La evidencia del consenso como fórmula fue visible en todo instante de la postdictadura. La negociación permanente con los tres mosqueteros que garantizaron la obra: la derecha, el empresariado y las fuerzas armadas (Baño, 1992: 136), supuso una particular sensibilidad por la disidencia. En el fondo "(se le encarga) a la fórmula del consenso la tarea de neutralizar los contrapuntos diferenciadores, los antagonismos de posturas, las demarcaciones polémicas de sentidos contrarios" (Richards, 2007: 134); consolidándose la idea de la ausencia de formas de disidencia como la señal más clara de una voluntad de sostener la democracia y de no convocar los grupos que detentan la violencia. Como señala Camargo en una investigación sobre la elite política y sus procesos de reconstitución de identidad, el consenso no corresponde a un ejercicio de racionalidad política, sino que se configura como una manera traumática de reconstrucción de la identidad de una generación política marcada por el Golpe de 1973. Este ‘consenso traumático’, dirá Camargo, caracterizado por el odio al conflicto, constituiría una clave explicativa decisiva de la vida política chilena post dictatorial (véase Camargo, s/f).

Si bajamos la mirada desde la elite política a la ciudadanía, la noción de consenso se articula con un fenomenal deseo de orden social. En este sentido, parece haber también el predominio de una forma traumática de comprender la cuestión de los acuerdos, el consenso y el orden. La percepción de que las diferencias terminan 
Memorias del Subsuelo: Exploración de la Economía de los Valores en el Chile Actual / Alberto Mayol Miranda

en violencia, con su ecuación concreta de que la suma de civiles en desacuerdo es igual a militares, redunda en que el consenso aparezca como la versión discursiva de la conquista de la paz y el orden, concepto - este último- vaciado de nociones sustantivas.

De cualquier modo, la forma en que se conecta el orden con un conjunto de otros valores merece un examen detenido, por la importancia en el discurso sobre valores públicos que emerge en los hablantes. El orden se ha constituido en un bien de salvación $n^{13}$ esencial en nuestra vida política. Se torna un valor político de la misma estatura que la libertad, la igualdad o el progreso (que son los valores políticos esenciales del proceso de modernización, los más llenos de significado). A tal punto es así que es un agente estructurante en términos culturales de otras significaciones y juicios.

En Chile el orden compite con otros valores troncales mano a mano.Y se percibe incluso al ponerlos en competencia en una encuesta. Como se aprecia en el siguiente gráfico, resultante de una encuesta probabilística realizada en junio del 2007 en las ciudades de Santiago,Viña del Mar,Valparaíso y Temuco; el orden adquiere una importancia sorprendente en la ciudad de Santiago, donde se instala con $1 / 4$ del total de preferencias, aun cuando consigue una presencia relevante también en las otras ciudades. Es llamativo, en todo caso, que sea Santiago el lugar donde el orden tenga más presencia, siendo el orden un valor presuntamente heredero de formas más tradicionales que la igualdad, la libertad y el progreso. Por tanto, sería pensable que su relevancia debiera estar vinculada a entornos más tradicionalistas (y siendo así la presencia del orden debiera ser más intensa fuera de Santiago).

13 Weberianamente los ‘bienes de salvación' son atributos cuya posesión es camino, señal o garantía de virtud o fortuna, a la vez que la esperanza para conseguirlos dota de sentido las acciones. Religiosamente son directamente los atributos cuya posesión es garantía, al menos relativa, de salvación. Ellos pueden ser mundanos o extramundanos. Uno de los bienes de salvación más habituales es la riqueza, que ha sido el de muchas profecías mundanas (también son habituales la salud, la longevidad, la liberación del sufrimiento y la evitación de la muerte). La relación entre ética y 'bienes de salvación' es permanente y son las transformaciones de la primera las que exigen a los segundos nuevas articulaciones que sustenten la unidad de sentido (véase Weber, 1996). Son bienes en tanto son apropiables y se puede excluir a otros de su posesión. Se pueden caracterizar como valores de alta densidad social, capaces de articularse históricamente. Saltan desde la esfera de lo valorado a la esfera de constitución de bienes simbólicos relevantes en la articulación de la acción social. En las sociedades contemporáneas resulta evidente que aparecen también -de un modo no religioso- los bienes de salvación. Se han secularizado y operan como si fueran de salvación, pero tienen un sentido diferente. Se constituyen en bienes culturales de referencia social ineludible, bienes de orientación de sentido, que vacíos de su sentido original, siguen siendo capaces de articular los deseos y necesidades 


\section{Gráfico 1:}

Respuestas a la pregunta: "Si tuviera que elegir uno de los siguientes valores como el más importante para que lograr tener la sociedad que a usted más le gusta, ¿Cuál elegiría?”

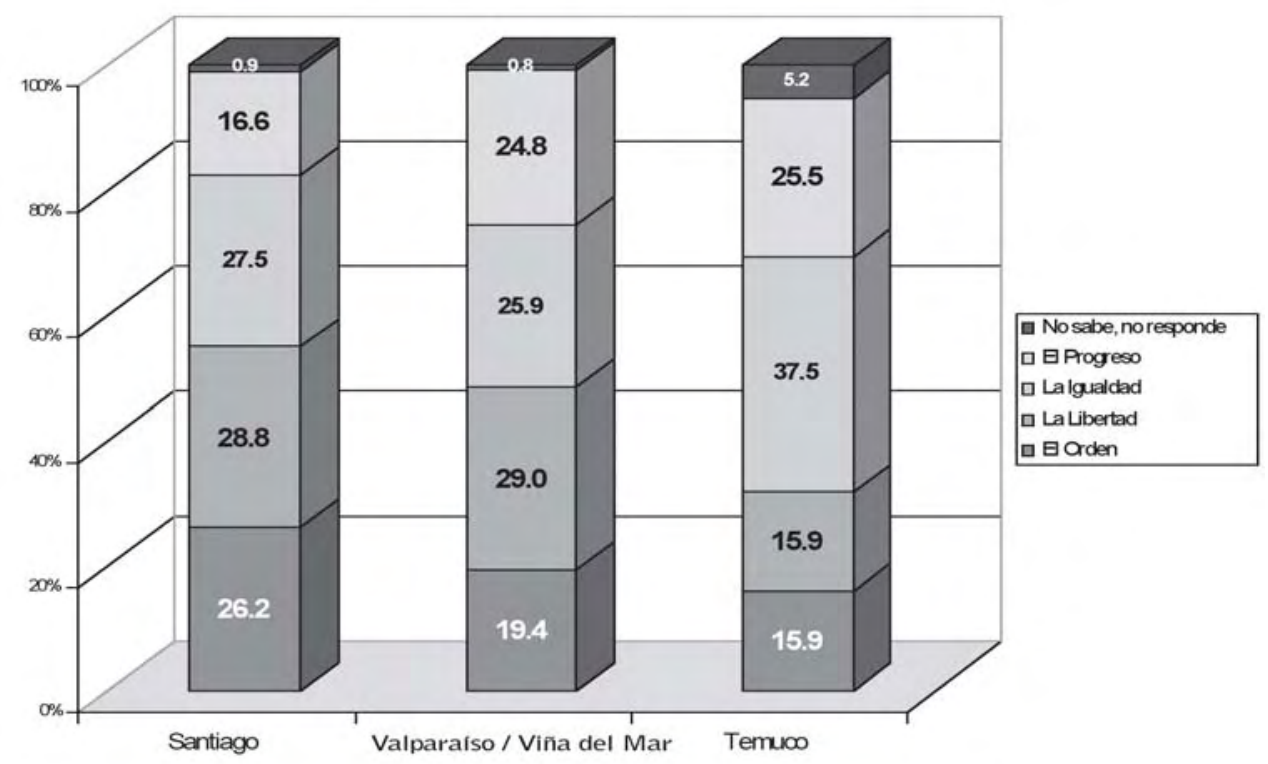

El fenómeno es muy interesante pues los valores en competencia, seleccionados a partir de los ejes discursivos más saturados a la hora de referir a los juicios evaluativos de la sociedad, son en general valores propios del proceso de modernización y sus profecías. La conquista del orden fue subsumida en la Modernidad, pero constituye más bien una relectura del deseo de estabilidad que los procesos de modernización cuestionan con sus tendencias a las transformaciones. Esta base interpretativa es fundamental para intentar comprender lo que ocurre con el 'orden' en Chile. Pues en la ciudad más modernizada es donde más se recurre a él, en desmedro del progreso como valor. Ello puede resultar paradojal y desde ciertas visiones interpretativas ese juicio es razonable. Pero hay conjeturas que nos pueden otorgar sentido respecto a este asunto: Santiago es una ciudad más desarrollada que el resto de las urbes del país. No hay experiencias conocidas de casos en los que grupos humanos que han progresado asuman que ya han conseguido su objetivo y por tanto cambian de valor. La búsqueda de riqueza y abundancia suele no tener límite superior. Por tanto, debemos descartar la posibilidad de que los santiaguinos hayan dejado en un plano secundario al progreso. La tesis que defendemos aquí es que es el orden el que adquiere una importancia consular y no el progreso el que disminuye su relevancia. Y la explicación que se puede bosquejar a partir de lo cualitativo es la importancia que se le atribuye al vínculo masividad-desorden-barbarie. Santiago es una ciudad 
Memorias del Subsuelo: Exploración de la Economía de los Valores en el Chile Actual / Alberto Mayol Miranda

significativamente masiva, no sólo en su cantidad de población, sino en la presencia del comportamiento propio de las masas. En este tipo de entornos las condiciones de integración se alejan de las configuraciones comunitarias. La pérdida de estos lazos aparece como una pérdida significativa para los sujetos, al punto no sólo de la sensación de una cierta anomia, sino incluso al nivel del temor al otro como sujeto potencialmente belicoso, agresivo.

Es pensable entonces -y veremos cómo se configura discursivamente- que la necesidad de un control de los rasgos propios de una sociedad de masas alimente una necesidad de orden. Tironi ya señaló algo en este sentido al decir que los grupos más privilegiados de nuestra sociedad se han sentido amenazados por la irrupción de las masas, por lo que se han propuesto disciplinar las expectativas y constreñir los grados de libertad (Tironi, 1999). La sensación de que el incremento de la libertad pueda conducir a la anomia y la desintegración es un elemento interesante en este análisis y engancha adecuadamente con lo detectado empíricamente.

La producción del orden aparece permanentemente en los discursos como un elemento articulador de la vida social, encontrando en muchas ocasiones discursos subsidiarios de gran importancia. Entre ellos -indudablemente- está el tema de la delincuencia y todas aquellas amenazas que son vistas como desviaciones violentas del orden. Este discurso cruza diferentes ideologías, siendo frecuente apreciar la idea del orden como el control de un pueblo que se descontrola en búsqueda de beneficios, que pierde la virtud de conservar su lugar en la sociedad y que eventualmente deja de temer a la autoridad (el eficaz 'temor a Dios' del Antiguo Testamento). De este modo, ante el desgaste del orden será necesario reproducirlo.Y en esa búsqueda emergen tres medios fundamentales:

- la violencia como represora del desorden: “hay que ser más duro” es un mensaje reiterado en los hablantes, con una asociación implícita o explícita a que el fin de la dictadura generó cierta sensación de fin de los castigos por pasarse de un gobierno militar a uno civil. La gravedad de la delincuencia para el orden se expresa en las tradicionales referencias a la delincuencia como un 'flagelo' que destruye la sociedad.Y la preocupación por ella sigue subiendo en las encuestas (en la última encuesta CEP de Noviembre-Diciembre de $2007^{14}$, la delincuencia sube del $50 \%$ de las preferencias como el principal problema a solucionar por el gobierno, al 59\%; siendo seguido muy de lejos por la salud, la pobreza y la educación). Lo más notable, de cualquier modo, es el carácter explícito de la importancia de las formas punitivas como forma de solución: $52 \%$ considera que los jueces deben ser más duros con los dete-

14 Para mayor información sobre esta encuesta probabilística de 1505 casos realizada en 153 comunas del país, véase CEP (2007): Estudio Nacional de Opinión Pública N 56. Noviembre-diciembre 2007. Dirección web: http://www.cepchile.cl/ 
nidos, a los que se suma el 13\% que desea aumento de dotación de la policía y carabineros, el 6\% que dice que se debe ser más duro con el narcotráfico y un 7\% de encuestados que considera que la solución está en alguna clase de medida con relación a las cárceles. La importancia de las oportunidades de trabajo sobre este tema (15\%) y de mejorar los programas de rehabilitación (7\%) no constituyen rivales valorativos de peso ante la visión de lo imprescindible que parece resultar el uso de la violencia y su insensibilidad ("hay que ser más duro") para la conquista del orden.

- las leyes como generadoras del orden legítimo: ya sea vía la necesidad de nuevas leyes o la necesidad de una aplicación más rigurosa, la ley es una forma considerada eficaz en la producción del orden.

- la conservación de tradiciones y/o instituciones: el orden se sostiene en costumbres, tradiciones e instituciones que deben permanecer en su existencia por el solo hecho de que otorgan continuidad al orden ("no pueden cerrar esa empresa, siempre ha existido y es importante que siga", "Valparaíso se está muriendo porque han sacado todas las instituciones importantes, han cerrado los colegios tradicionales, se han ido las industrias").

La dictadura de Pinochet y fundamentalmente su Golpe de Estado como momento excepcional supuso el desgaste de las leyes. La violencia es desgastante en lo simbólico, por lo que tuvo que anclarse en una mirada tradicionalista. De algún modo reivindicó las formas del antiguo régimen, un conservadurismo portaliano con un giro no republicano, reencontrándose con los valores coloniales perdidos (la milicia y la religión). El elemento por destruir es la República. Por eso encuentra en el franquismo una inspiración, ya que comparten el enemigo común de la República y sus valores.

La interpretación del golpe es la de una culpa colectiva. Esta noción culposa puede tener distintos alimentos (posiblemente no sea menor que la misma clase política haya vuelto a la actividad después de la dictadura), pero en cualquier caso explica la timidez generalizada respecto a los temas asociados al período autoritario. El golpe de Estado es interpretado como una caída (necesaria o innecesaria, pero siempre caída), de la cual hay que levantarse con la cabeza gacha y habiendo perdido derechos.

Sin las leyes ni los valores republicanos de por medio, la búsqueda del orden queda inerme y con base compulsiva e irracional. El orden pasa a ser la mera ausencia de conflicto, consumándose así (el orden) como la producción permanente del consenso, que no es un método, sino una compulsión y una arbitrariedad. El consenso se transforma en un conjunto vacío, en mera forma capaz de absorber en su interior todos los contenidos y vaciarlos lo suficiente como para producir un orden carente de energía. El consenso es fuerza desmovilizadora, envase para un acuerdo vacío de contenido. 


\section{Memorias del Subsuelo: Exploración de la Economía de los Valores en el Chile Actual / Alberto Mayol Miranda}

Los procesos de legitimación del orden se desgastan, pues el proceso de legitimación, el fundamento, la expresión sensible y el espíritu del orden se confunden en el consenso. La diferencia social no puede expresarse activamente, pues lo rompería. El poder y la riqueza dejan de requerir formas legitimadoras. La mera reproducción del orden legitima de por sí. De ser insuficiente, la compulsión del consenso anulará el conflicto. El que no acepta o no busca el consenso, es incivilizado y políticamente irresponsable. Es él quien se constituye en culpable de que pueda aparecer la violencia, que late en el fondo como productora de orden.

La timidez frente a la violencia se ha ido perdiendo y hoy se le solicita con frecuencia frente a las desviaciones. La delincuencia, fundamentalmente, o cualquier desorden (interpretado en lo inmediato como delincuencia); requieren la apelación al uso de la violencia con fines estabilizadores. El desorden, el caos, es un llamado directo a la violencia. La noción de que el caótico insurrecto está pidiendo la violencia es persistente ("después no reclamen, ellos lo quisieron”).

Ahora bien. Aún no desagregamos el concepto de orden. En este sentido es fundamental comprender que el concepto de 'orden' no es unidimensional en distintos actores sociales. Esto resulta muy evidente en la investigación cualitativa, donde el orden adquiere una doble faz según el nivel socioeconómico de los hablantes.

A medida que bajamos de nivel socioeconómico, el problema del orden tiende a relacionarse con la cuestión de la estabilidad y la conservación del orden en el mundo en un sentido antropológico. Esto es, se trata de defender la cultura, la civilización. Nos retrotrae fuertemente a la visión de Lévi Strauss sobre el origen de los modales. El orden provee del potencial integrativo que faculta a los individuos para constituirse en seres humanos en su sentido pleno, pasando al estatus de miembros de una sociedad. El orden conserva los rasgos de humanidad. Esto explica el miedo a la degradación, a la pobreza y a la decadencia como pérdida de atributos humanos. Se expresa en continuos lógicos como: "el Transantiago es un caos", "el Transantiago es una ofensa, no hay respeto", "nos tratan como animales". La deriva caos-ofensa-animalidad es la referencia a la degradación. La pérdida del orden conduce a una caída en la condición zoológica ${ }^{15}$.

15 Ver los antecedentes coloniales de este asunto en DUVIOLS, Jean Paul (2000): "Percepciones e Imágenes del Mundo Americano a través de los Primeros Testimonios" en Pease, Franklin (2000): Historia General de América Latina, tomo I, el primer contacto y la formación de nuevas sociedades. Madrid: Ediciones UNESCO, Ediciones Trotta. Late en esta temática un viejo juicio, dirigido en la Colonia a los indígenas, último estamento de esa época, según el cual se les señalaba a estos -en una versión recurrente aunque no única- en el límite de la humanidad, bajo la percepción de que se percibe en los indígenas un barbarismo repulsivo y condenable (pág. 492), con el permanente rótulo de 'animalidad' como juicio posible. También en la era colonial será normal asociar las faltas y desviaciones al caos y éste a la masividad (en semejanza con observaciones también realizadas en este artículo). Como señaló el jesuita José Cardiel, presumiblemente en 1768, “en tan crecida muchedumbre, no faltan pecados, los cuales como delitos de niños, se castigan con azotes, cárcel y cepo" (Duviols, 2000: 503). Estas afinidades sólo nos revelan la necesidad permanente de vincular nuevas manifestaciones culturales con viejos esquemas valorativos, cuya operación podría gozar aún de eficacia. 
A medida que subimos de nivel socioeconómico, el problema del orden se vincula crecientemente con la conservación de la estructura social. El orden reproduce las distancias de clase y hasta las aumenta. Los sujetos pretenden atomizarse crecientemente, alejarse y diferenciarse, pues ello les garantiza la permanencia de su superioridad. La distancia purifica porque la sociedad es un agente desordenado y contaminante. Hay un razonamiento de casta en el sentido en el que describe Weber la religión hindú: estamentos hereditarios estrictos y exclusivos que se caracterizan por posiciones fijas en la pirámide social, produciéndose un evento de 'contaminación ritual' cuando miembros de distintas castas interactúan directamente. La convergencia espacial -en el hinduismo- está derechamente prohibida, pues afecta al orden y genera inconvenientes para todos los involucrados. La presencia de miembros impuros de la comunidad, esto es, no sólo miembros de la comunidad de clase inferior, sino además sujetos que pertenecen a 'pueblos parias' que desarrollan labores productivas importantes, pero que no pertenecen a la comunidad y son completamente 'impuros'; debe estar regulada. De no ser así, se produce el caos y un radical cuestionamiento de las bases mismas del orden social (Weber, 1998b). Esto, que en la experiencia de la India y brahmanismo nos parece tan distante, es muy semejante a lo que ocurre -en una versión profana o al menos semiprofana- al interior de los segmentos con ingresos más altos de la población en Chile. La percepción del otro como contaminante y, ante todo, de las masas ilegítimas (de los otros 'fuera de control') como sujetos impuros capaces de destruir lo más valioso de la vida social; es una norma permanente.

Esto explica la tendencia de los grupos con mayores ingresos de construir una distancia objetiva y claramente delimitada en lo espacial.Vivir lejos, fuera de la ciudad, lo más ajeno a la sociedad, tiene un sentido preventivo frente a la contaminación ${ }^{16}$. El argumento se ha constituido como una conjetura de cierto riesgo, por lo que se ilustran algunas citas que permiten sostener -al menos a la manera de lo plausible- el análisis:

"Me molesta de la sociedad el desorden; como que eso lo asocio a contaminación. (Me gustan) las cosas bien distribuidas, espacios solitarios."

"La vida ideal es descontaminación. Con espacio, naturaleza, trabajo, una familia feliz...todo con fácil acceso. (silencio breve) Fácil, amigable con todas las cosas. Todo con Internet...; poder ir al supermercado, tiendas, esas cosas".

"Por ejemplo, una ciudad limpia. El asunto de la contaminación, el smog. Una ciudad libre de congestión vehicular.".

16 Informes recientes dan cuenta de la marcada tendencia en las migraciones intrtaurbans en Santiago a una creciente segregación. Los grupos más acomodados han innovado en nuevos espacios en ciertas comunas (Huechuraba, Peñalolén y Colina por ejemplo), pero lo hacen bajo una lógica de distanciamiento y aislamiento, generando condominios cerrados y otras formas de producción de distancias. Véase al respecto ORTIZ J. y ESCOLANO S. O "Las Migraciones Intrametropolitanas como Factor de Diferenciación Socioespacial". Ponencia en el taller de población del CELADE. En Internet: http://www.eclac.org/celade/noticias/paginas/5/28295/JOrtiz.pdf. Los autores señalan que "el patrón descrito viene a reafirmar (...) que los desplazamientos poblacionales tienden a acentuar las diferencias espaciales preestablecidas en la sociogeografia de la ciudad" (página 10). 
"Creo que es vital tener una ciudad limpia y ordenada, sin congestión. Influye en la calidad de las personas. O sea, una ciudad sucia, congestionada, es un problema de salud pública; es el origen de todas las enfermedades".

La gente acumulada en sus distintas formas es 'congestión'. La sociedad, por tanto, es congestión y es por definición desordenada. Esta congestión es sucia y por tanto contamina, constituyéndose en fuente de males (enfermedades). Es discurso redunda en las siguientes asociaciones:

\section{Esquema 1: Análisis Paradigmático de los Discursos de los Sectores de Altos Ingresos}

\begin{tabular}{|c|}
\hline Sociedad / Individuo \\
Tumulto / Tranquilidad \\
Desorden / Orden \\
Congestión / "Espacio" \\
Roce / Fluidez" \\
Obstáculos / Libertad \\
Contaminación / Pureza \\
Confusión / Diferencia \\
Proximidad / Distancia \\
Suciedad / Limpieza \\
Enfermedad / Salud \\
\hline
\end{tabular}

De este modo, el orden se articula con los sistemas de valores propios de la pureza, la distancia y la diferencia, constituyéndose en un elemento estructurante en lo cultural de las distintas posiciones en el espacio social ${ }^{18}$. Esta deriva hacia la forma 'casta'

\footnotetext{
17 Esta tensión es vital en los segmentos más altos de la población. La fluidez pasa a ser un 'bien de salvación'. Debo este concepto (el de fluidez por cierto) y sus primeros análisis a la confluencia de Eduardo Thayer con un par de transcripciones de grupos de discusión. Fue él quien detectó la tensión fluidez/roce. La ruta de la fluidez es de gran interés, a mi juicio, y las recopilaciones empíricas realizadas en los grupos privilegiados de nuestra sociedad así lo corroboran. Un análisis más detenido sobre la sorprendente necesidad de fluir de los miembros de la elite merece el mayor detenimiento. Hay sin duda un estatus asociado a la fluidez: quien consigue evitar el roce, lo hace en la medida de sus privilegios, tornándose en símbolo de posición social. La fluidez se compra permanentemente, es una necesidad inagotable de alta simbología en el proceso de distinción. Pero hay una segunda ruta de cierto interés: tomar suficientemente en serio los dos datos centrales y transformarlos en pregunta. ¿Por qué los grupos con más dinero desean tanto la fluidez? En este sentido es viable una conjetura que queda planteada como posibilidad: el dinero aparece en los grupos de mayores ingresos como un objeto de deseo particularmente cargado de catexis. La atracción del dinero puede generar entonces la búsqueda de identificación con el objeto de deseo, ya que es un objeto de prestigio social y éste es un grupo que vive de ese prestigio. Ante esto, el sujeto quiere ser el dinero (quiere ser el prestigio, su forma material).Y el paradigma del dinero sofisticado y glamoroso del mundo contemporáneo es la economía financiera, los fondos que ‘fluyen' de un espacio a otro sin roce alguno. La necesidad de fluir completamente parece ser entonces el deseo de dejar de ser un sujeto lleno de las limitaciones propias de la vida social (y del cuerpo y su caducidad), para pasar a ser capital transnacional (con su eterna fluidez). Dejo constancia de que esta aventura interpretativa es de responsabilidad del autor y no del Dr. E. Thayer a quien debo la etapa no delirante del análisis, que termina justo antes de la segunda ruta de análisis en esta nota descrita.

18 Se debe destacar que el continuo orden-pureza parece fundamentar en gran medida un incremento alternativo de la vida espiritual, ya sea en formas místicas y/o doctrinarias, emergiendo así el discurso de la posibilidad
} 
merece una atención especial en tanto emerge la obvia necesidad de comprender cuánto hay de 'normal' en este proceso cuando hay aumentos en las desigualdades o cuánto hay de productor de la diferencia este mismo proceso.

En este sentido, el proceso de naturalización de la diferencia se asocia a una moralización de la posición social. La situación en la escala social se transforma en un contenido en sí mismo, adquiriendo 'valor'. Estar arriba es un hecho que se fundamenta a sí mismo y por tanto se torna ilegítimo el movimiento ascendente. Conocer el movimiento es descrédito. En Chile no hay procedimientos eficaces de 'lavado de origen', como sí los había en la India descrita por Weber. Este elemento complejiza los procesos de ascenso social, entregándole también un carácter traumático permanente (donde es posible que el consumismo cumpla un rol relevante como símbolo enfermizo de una diferencia que no se logra naturalizar completamente).

En el marco de la estructura social, al concentrarnos en los grupos de más ingreso, que en Chile se encuentran a gran distancia de los grupos menos privilegiados (recordemos que Chile está entre los 10 países más desiguales ${ }^{19}$ ), detectamos entonces una sintomatología importante de las consecuencias perversas de la distancia social creciente en los marcos normativos y valorativos. De cualquier modo, es evidente que en este sentido se aprecia un proceso de transformación aún en curso, cuya ruta queda relativamente trazada por el esquema presentado anteriormente (esquema 1).

\section{3) Tres Profecías en el Chile Actual}

Como se ha apreciado, no ha sido infrecuente en este texto la utilización de conceptos que provienen de la sociología de las religiones de Weber. La regularidad no es casual, como resulta evidente a quienes trabajan en ciencias. Resulta que el uso de categorías religiosas en los estudios culturales parece ser inevitable. Uno de los argumentos de mayor recurrencia es el que señala que la cultura en su forma moderna es un residuo de las formas religiosas del pasado (Habermas, 1999). Esto es evidende vinculación espiritual con la divinidad y/o el mundo. Este tipo de fenómenos merecen una atención más detallada, pues revelan nuevas necesidades de construcción de sentido sobre las relaciones comunitarias.

19 El tema de la concentración del ingreso es en Chile más sorprendente de lo que el Índice Gini y sus rankings internacionales nos señalan (Chile entre los 10más desiguales del mundo). Como demostró Florencia Torche con su presentación "Patrones de Estratificación en Chile en Perspectiva Comparada" realizada en la reunión de expertos de la CEPAL realizada el 21 de diciembre de 2007, si comparamos el índice de Gini de Chile con el mismo índice, también para Chile pero excluyendo al 10\% más rico de la población, Chile pasa de ser un país muy desigual a ser uno bastante igualitario. Es decir, la desigualdad del $90 \%$ menos rico de la población no es particularmente alta, siendo no muy amplia la distancia de ingreso entre capas medias altas, medias, medias bajas y bajas. Chile se torna un país notoriamente desigual al agregar al 10\% más rico de la población. Este no es un fenómeno común, pues al mismo ejercicio el resto de los países latinoamericanos sólo bajan un 20\% ó 30\% su Gini al excluir al decil más rico, mientras Chile lo hace en un 50\% aproximadamente. Lo más notable es que si en Chile se excluye al 10\% más rico, el país se transforma en bastante igualitario, mucho más que el conjunto de los países latinoamericanos y que Estados Unidos incluso al mismo ejercicio. Es decir, el Chile país del tercer mundo es bastante igualitario y notoriamente masivo. Pero el Chile rico, con habitantes de ingreso primermundista que concentran casi el $40 \%$ de los ingresos en el 10\% de la población, agrega una nueva realidad que hace disparar el Gini hacia niveles sorprendentes. 
Memorias del Subsuelo: Exploración de la Economía de los Valores en el Chile Actual / Alberto Mayol Miranda

temente cierto en perspectiva histórica, pero la razón de fondo es aún más profunda. En rigor, las formas simbólicas religiosas (ritos, mitos, símbolos sagrados, entre otros) y las formas organizacionales de las religiones (sacerdocio, profeta, mago, iglesia, secta, entre otros) constituyen fenómenos de indudable vinculación con la sociología de la cultura, ya que se constituyen en el proceso de determinación de las formas simbólicas o en el proceso del producción o control de las mismas. Entonces, debemos pensar en la religión como un fenómeno que expresa muy bien las configuraciones de la cultura. Y no al revés. La inexistencia de una cultura secular previa a la era moderna y el hecho de que las imágenes de mundo religiosas fueran históricamente precedentes, no torna conceptualmente anterior a la religión por sobre la cultura.

Pues bien, fundamentado el hecho de recurrir permanentemente al lenguaje de la sociología de la religión en medio de un análisis profano; es posible pasar a la cuestión de las tres profecías que se encuentran presentes en el Chile actual. En definitiva, a partir de la configuración cultural antes descrita, donde el orden y el consenso se tornan bienes cuya posesión debe garantizarse, la respuesta simbólica es la articulación de tres profecías que cumplirán un rol desmovilizador, despolitizador y fundamentarán la mirada de una fórmula aséptica de ejecutar las decisiones políticas.

Articulándose bajo la promesa de la abundancia o riqueza, en el imaginario de la multiplicación, el progreso material y el deseo individual del beneficio, emerge un marco simbólico constituido por un conjunto de necesidades consideradas vitales para la satisfacción del horizonte que esta promesa muestra.

- Necesidad de producir decisiones y visiones ajenas a los conflictos superficiales de la política contingente (necesidad de salir de la política).

- Necesidad de producir riqueza, bajo las enormes exigencias de la aspiracionalidad y de la preeminencia del bien de salvación 'riqueza' por sobre el resto de estos bienes ${ }^{20}$.

- Necesidad de re-sacralizar la toma de decisiones de un modo tal que su cuestionamiento se haga difícil por las masas y permita un bloqueo desde la elite.

Una profecía altamente fructífera para satisfacer necesidades es el otorgamiento del poder a la 'visión técnica', entendiendo lo técnico desde una perspectiva economicista. Este discurso toma su configuración como grupo a la manera de una 'tecnocracia' o clase de especialistas con poder de decisión. Esta promesa desvía la atención de la

20 La cuestión del imaginario de la riqueza para Chile quedará sin suficiente desarrollo en este artículo por la necesidad que supone de vincular mucho más discursos de autoridades, expertos y ciudadanos, lo que redundaría en un texto monográfico al respecto. De cualquier modo, es relevante recordar la observación de Jorge Larraín respecto a la permanente alusión a un deseo por pertenecer a la comunidad de los países desarrollados, que llegó al punto en que la Concertación definiera como objetivo el acceso al desarrollo el 2010 (Larraín, 2001) y que este año se asumió como imposible, pero se proyectó para el 2020 por parte del Ministro de Hacienda, Andrés Velasco. 
Revista de Sociolocía 21 / 2007 Chile Hoy

Facultad de Ciencias Sociales - Universidad de Chile

lógica política de pactos sociales, derechos, obligaciones, ciudadanía, legitimidad, entre otros elementos; hacia la eficacia y eficiencia, prometiendo la existencia de resultados positivos por esa ruta, apelando a una mirada realista, operativa y rentabilizadora. Esta profecía está funcionando de un modo fértil en todos los niveles, pues se detecta en el discurso político y toma una forma muy dúctil y adaptativa a nivel masivo con dos ideas: la de la necesidad del tránsito del conflicto político al consenso técnico y, en segundo lugar, por la idea del emprendimiento. La primera de estas ideas, entroncada con la lógica del consenso y su consecuencia de clausura ideológica, queda muy clara en una entrevista realizada a Pablo Longueira en el año 200121:

"Después del gobierno militar, yo creo que el cambio es tan profundo en el sentido de que en Chile va haber por mucho tiempo respeto a la democracia que antes no existía antes del 11 de Septiembre. Ahora ningún partido político puede hacer planteamiento como los que hubieron en el pasado en materia de no valorar la democracia, por lo tanto, Chile tiene un sistema político en que podremos discutir muchas normas de nuestra institucionalidad, pero en Chile no hay ningún partido político relevante que no sea democrático. Si miramos también (...) el tema económico social también es un tema en que hoy día hay una cancha muy bien rayada, es un país que tiene una economía abierta en un mundo cada vez más globalizado en que las líneas gruesas del sistema económico y social tampoco van a ser modificadas sino que están dentro de rayado de cancha que es legítimo" (Pablo Longueira, 2001).

"Para mí lo importante es fijar criterios técnicos, de parámetros mínimos en que consideramos que esa persona tiene dignidad y que la sociedad le permite ser digno, ya sea jubilado, allegado, temporero, trabajador, lo que sea.Y eso para mí, es un criterio que si uno se aproximara a ese punto de vista uno debiera llegar a ciertos consensos, podemos discutir si hay más o menos parámetros para llegar a ese nivel de dignidad, pero en una discusión técnica, es una discusión de políticas públicas, en que tenemos que concordarlas, discutirlas, pero desde ese punto de vista, no la discusión política de la confrontación sino que es una... en el fondo es analizar la pobreza como ya se analiza la economía" (Pablo Longueira, 2001).

Esta idea del acuerdo técnico como forma superior del consenso, que supone que los fines valorativos (dignidad en este caso) son cuantificables y susceptibles de resolución técnica, representa notablemente el espíritu de la elite política y económica en los últimos años. En la búsqueda de respuestas técnicas unívocas en contraposición con las amplias avenidas de la política, el rol de los economistas neoclásicos (conocidos como neoliberales) ha sido sin duda decisivo. Como señalaVerónica Montecinos sobre el caso chileno y en el marco de la instauración -con Pinochet- de los actores tecnocráticos como sujetos de gran relevancia política:

21 La entrevista fue realizada por Tatiana Hernández para efectos de una investigación realizada por ella con fines distintos a los aquí buscados. Agradezco la posibilidad de haber dispuesto de esta transcripción y otras de su estudio. 
Memorias del Subsuelo: Exploración de la Economía de los Valores en el Chile Actual / Alberto Mayol Miranda

"La búsqueda de renovación política, de nuevas formas de discurso político, nuevos símbolos y nuevas imágenes -junto a la imposibilidad de comparar fuerzas en elecciones competitivas- permitió a los economistas jugar un papel, no sólo en la lucha de los partidos por sobrevivir, sino en la 'modernización» de la política'. El llamativo despliegue de economistas indicaba la conformidad de los partidos con algunos de los rituales nuevos, que presuntamente garantizaban legitimidad política: el interés por la eficiencia, la estabilidad macroeconómica y la competitividad internacional" (Montecinos, 1997:16)

El rasgo profético del discurso tecnocrático es evidente ${ }^{22}$. En ese sentido, el tono religioso con el que se refieren los actores sociales y medios de comunicación a los enunciados de los economistas no es un evento extraño. Los mismos tecnócratas lo utilizan. Adelio Pepino ${ }^{23}$, quien fue encargado de la 'Página Económica' que el periódico El Mercurio en sus primeros años, antecedente de lo que después se constituyó como el 'cuerpo económico', señala: “(la Página Económica fue) la aparición del Monasterio a la vida pública (...) los monjes muestran al exterior esta nueva ciencia del problema económico que vino a reafirmar y profundizar una prédica central (...), pero que aportó nuevas ideas. Los médicos reemplazaron a los curanderos" (Soto, 2003: 59). La descripción aquí realizada es sorprendente por la metáfora utilizada: las ideas de salto científico, de salida de una sabiduría oculta en las celdas monásticas a la calle (¿una nueva Reforma en el sentido de la protestante?) y de rol iluminador se superponen en un sólido constructo discursivo e ideológico.

La técnica también se superpone a una búsqueda concreta por contenidos civilizados. En un residuo del discurso ilustrado, fragmentado en una forma cientificista y restringida ${ }^{24}$, el discurso técnico apela a una presunta superioridad civilizatoria de la formulación científica por sobre la decisión política. Sin embargo, si quisiéramos apelar al contenido civilizatorio, éste es ostensiblemente más complejo en términos culturales. Hay una búsqueda de control de las desviaciones, de mantenimiento de las diferencias sociales y de producción de la civilización que encuentran su expresión más marcada en un valor ya analizado: el orden. Esto ya ha sido señalado. Sin embargo, es necesario agregar un elemento más y es que el orden se constituye en un bien de salvación profano y de alto contenido político, que se sustenta en la profecía de la violencia. El mensaje profético es siempre instrumental a la divinidad (Weber, 1996). El rasgo superior y trascendente del orden supone que haya una garantía -también superior- que se consuma en la profecía de la violencia, un mensaje de temor y pérdida del medio de salvación.

22 Para un análisis desde la teoría de la racionalidad de la promesa tecnocrática, véase MAYOL, Alberto (2003): "La Tecnocracia: el Falso Profeta de la Modernidad" en Revista de Sociología. Número 17, Año 2003. Páginas 95-123. Santiago. Facultad de Ciencias Sociales, Universidad de Chile.

23 Economista de una de las primeras generaciones que se formó en el marco del convenio de la Universidad Católica de Chile con la Universidad de Chicago.

24 Es ilustrado en la medida en que apela a un racionalismo marcado y se conecta con utopías cientificistas que de algún modo fueron parte del discurso ilustrado. Pero no lo es en la medida en que restringe el proceso de secularización a la cientifización y que se desentiende de visiones sustantivas de la política como la importancia de la crítica social y de los valores propiamente políticos del proceso. 
Sin embargo, no se debe descuidar el otro punto señalado: la creciente consolidación de un proyecto ético bajo el rótulo del 'emprendimiento'. Éste adquiere estatus de ética, en tanto los actores pueden llegar a pensar que el éxito económico es un resultado de un tipo de actitud, de un conjunto de conductas y que carece de arraigo en fenómenos estructurales. En este sentido, es muy interesante el choque que se produce entre esta mirada y la que es propia del imaginario de la lucha de clases, forma que aparece como elemento resistente a esta ética. De cualquier modo, la tensión entre los imaginarios del emprendimiento (forma comercial de la aspiracionalidad) y de la lucha de clases refleja una situación de indefinición simbólica, pues ambos tienen fortalezas y pueden ser portados por los mismos actores sin que ellos vean la contradicción.

De cualquier modo, hay otros discursos que se imponen como 'necesidades' relevantes en la política. Se trata fundamentalmente de los valores políticos por excelencia: la libertad, la igualdad y la justicia, por ejemplo. La libertad en general es un concepto que adquiere rasgos de redefinición. Es posible que se trate de carencias propias de la forma de recopilación del material, pero hay indicios de una situación de revisión no unitaria del concepto de libertad, donde aparecen las cuestiones referidas a la libre selección de estilos de vida, a la libertad como consumidor, a la libertad en un sentido de proyecto de sociedad, a la libertad respecto a las tradiciones instaladas, entre otras. Bajo estas tensiones es posible estar vislumbrando rasgos de un proceso de transvaloración, lo que permitiría la comprensión de un cambio cultural hipotético. Sin embargo, una labor de esa naturaleza requeriría material diferente al que contamos, al tiempo que un enfoque en un período mucho más largo.

Respecto a la justicia y la igualdad, lo que se aprecia es un claro predominio de conceptos de justicia asociados a dos criterios: la necesidad de compensar una sociedad injusta y la necesidad de abordar el sufrimiento de los menos afortunados. Se esconde una noción evidentemente salvífica de la justicia, que aproxima este discurso a una visión caritativa. En este sentido, es evidente el entronque de este tipo de ética con el Estado subsidiario propio de las políticas económicas y sociales del modelo neoclásico, que como se aprecia ha generado un entronque culturalista altamente eficaz. Este vínculo ha generado una nueva fuente de legitimidad pública a la Iglesia, primera promotora del Estado subsidiario y que promueve la conmiseración y la caridad como valores asociados a la justicia. La Iglesia puede mostrar hoy un discurso público en perfecta consonancia con los valores instalados. Esto explica la paradoja de una Iglesia católica fuertemente ineficaz en sus políticas de renovación de fieles, fuertemente disminuida en practicantes y proclive a observantes distantes; pero que a la vez logra instalar temas en la agenda política con gran eficacia, al tiempo que multiplica las organizaciones (fundaciones) de ayuda social que operan bajo la lógica de que los actores privados beneficiados transfieren ayuda a los desposeídos a través de una organización intermedia. La profecía de la caridad adquiere aquí gran relevancia y se instala como 
Memorias del Subsuelo: Exploración de la Economía de los Valores en el Chile Actual / Alberto Mayol Miranda

fórmula de conquista de la justicia, en una visión que es altamente distante a las visiones republicanas sobre la justicia, donde el Estado es ante todo un aparato orientado al colectivo en su totalidad. Cuadro 1: Necesidades sobre las que dan cuenta algunas profe-
cías de la vida cultural chilena actual

\begin{tabular}{|c|c|c|}
\hline \multicolumn{3}{|c|}{ Profecías } \\
\hline Tecnocrática & $\begin{array}{c}\text { Violencia } \\
\text { Civilizatoria* }\end{array}$ & Caridad \\
\hline $\begin{array}{l}\text { - Necesidad de } \\
\text { producir decisiones } \\
\text { despolitizadamente } \\
\text { - Necesidad de } \\
\text { producir riqueza. } \\
\text { - Necesidad de re- } \\
\text { sacralizar la toma } \\
\text { de decisiones de } \\
\text { un modo tal que su } \\
\text { cuestionamiento se } \\
\text { haga dificil }\end{array}$ & $\begin{array}{l}\text { - Necesidad de } \\
\text { producir orden } \\
\text { - Necesidad de } \\
\text { producir civilización } \\
\text { - Necesidad de } \\
\text { controlar las } \\
\text { desviaciones } \\
\text { - Necesidad de } \\
\text { consumar las diferencias } \\
\text { sociales como } \\
\text { permanentes }\end{array}$ & $\begin{array}{l}\text { - Necesidad de } \\
\text { compensar una } \\
\text { sociedad injusta } \\
\text { - Necesidad de abordar } \\
\text { el sufrimiento de los } \\
\text { menos afortunados. } \\
\text { - Hacerse cargo del } \\
\text { proceso de salvación de } \\
\text { los condenados }\end{array}$ \\
\hline $\begin{array}{l}\text { * El hecho de que haya que recu } \\
\text { de la inmadurez de Chile. La prec } \\
\text { el libre criterio de los ciudadanos } \\
\text { a José M. Cea, donde dice: "La Re } \\
\text { ses? Un Gobierno fuerte, centrali } \\
\text { a los ciudadanos por el camino de } \\
\text { liberal, libre y lleno de ideales, dor } \\
\text { criterio pensará igual" (ver http:/ } \\
\text { todos los asuntos referidos a la del } \\
\text { contenido moralizante, que va tra } \\
\text { el trabajo y fundamentalmente co }\end{array}$ & $\begin{array}{l}\text { Ina violencia civilizatoria parece ser un } \\
\text { en el desarrollo civilizatorio obligaría a } \\
\text { urso decimonónico clásico al respecto } \\
\text { es el sistema que hay que adoptar; ¿per } \\
\text { uyos hombres sean verdaderos modelo } \\
\text { y las virtudes. Cuando se hayan moral } \\
\text { gan parte todos los ciudadanos. Esto es } \\
\text { accionchilena.cl/Historia/portales.htm) } \\
\text { cia y se hace evidente en la tendencia a } \\
\text { ndo claramente a una visión funcional } \\
\text { ortunidad de conquistar abundancia ma }\end{array}$ & $\begin{array}{l}\text { residuo de la famosa tesis decimonónica } \\
\text { que la violencia produzca el orden y no } \\
\text { stá en la famosa carta de Diego Portales } \\
\text { sabe cómo yo la entiendo en estos paí- } \\
\text { de virtud y patriotismo, y así enderezar } \\
\text { zado, venga el gobierno completamente } \\
\text { que pienso y todo hombre de mediano } \\
\text { Este discurso aparece muy saludable en } \\
\text { ninimizarse el rol de la educación como } \\
\text { le la educación en tanto formación para } \\
\text { terial. }\end{array}$ \\
\hline
\end{tabular}

Estas profecías se han articulado activamente en la forma del Estado Subsidiario, que se entiende adecuadamente en la formulación de quienes lo promueven, como es en la siguiente cita a Cristián Larroulet:

"A partir de 1973, con la caída del Gobierno de la Unidad Popular, se revierte el proceso (del Estado empresario) aplicándose un modelo de economía mixta en el cual el mercado es el principal mecanismo para asignar recursos, y el Estado asume un rol subsidiario. Este vela por el bien común general procediendo a intervenir para corregir deficiencias del mercado, tales como la presencia de situaciones monopólicas y de externalidades no deseadas. Asimismo provee de bienes públicos, y 
de condiciones de bienestar mínimas para los sectores más necesitados”25 (Larroulet, 1984).

Este tipo de concepto de Estado restringe el Estado a las labores de seguridad como único punto de contacto con el todo social y a las labores de compensar posibles efectos nocivos del mercado en grupos desfavorecidos. La focalización del gasto público, convertido de inmediato en social, supone la necesidad de saltos técnicos para poder asignar adecuadamente los recursos y para operar adecuadamente en la conservación del orden.

\section{4) La Internalización de la Desigualdad en los Marcos Valorativos}

La estructura social es interpretada por los actores sociales de modos diversos. Se asume que hay un intento por absorber e internalizar la realidad social de un modo adecuado a los marcos valorativos. En este sentido el despliegue discursivo de los hablantes suele conducir al juicio de una sociedad justa o injusta como la más poderosa distinción a la hora de incorporar la vida económica en la valorativa ${ }^{26}$.

El material de base con el que se ha trabajado no hace esfuerzos particulares por introducirse en la dimensión cultural de la estructura social. Sin embargo, la visión panorámica que emerge es el surgimiento de categorías muy gruesas para referir al hecho de unos pocos favorecidos y muchos perjudicados, en divisiones bastante duales. Es el caso de "ricos/pobres" o "ricos/clases medias"; "arriba/abajo" o incluso la ausencia de nombre para los más altos ingresos y su tensión con 'el pueblo' como descriptor de la pobreza. En este escenario lo más interesante va a ser cómo se construyen al menos tres relaciones entre los dos grandes grupos de la sociedad (ricos y pobres por ejemplo).

a) La relación que podría denominarse bajo el rótulo clásico de 'lucha de clases' y que se caracteriza por una mirada fuertemente anclada en la esfera laboralproductiva, donde la tensión empresario/trabajador es la central. La visión aquí es la de intereses colectivos contrapuestos y en general irreconciliables. Se asocia a cierta esperanza en la acción colectiva.

b) La relación 'resentida' reitera algunas características de la 'lucha de clases' en tanto 'pathos'. Sin embargo, hay una conversión en el 'ethos'. El resentimiento tiende a expresarse de un modo moralista, bajo la visión de la maldad del otro (superior en la escala social) en sus conductas respecto a sí mismo u otros.

25 Larroulet, Cristián (1984): "Reflexiones en Torno al Estado Empresario en Chile” en Documento de Trabajo del Centro de Estudios Públicos, №22.

26 El vínculo entre la estructura social y la dimensión cultural es posiblemente mucho más fructífero. La mirada aquí está restringida por el volumen del material empírico. De cualquier modo, el desarrollo de un conjunto de investigaciones a realizar en el Centro de Investigación en Estructura Social de la Universidad de Chile permitirá contar, ya en el 2008, con resultados relevantes sobre el entronque material-cultural. 
Memorias del Subsuelo: Exploración de la Economía de los Valores en el Chile Actual / Alberto Mayol Miranda

Sin embargo, el resentimiento parece ser la expresión de una desesperanza desmovilizadora. Hay visión de conflicto, pero el individualismo pasivo que domina esta mirada conduce más bien a una actitud doliente que sólo encuentra consuelo en la 'ruta cristiana' del dolor y su conversión en mérito. El resentimiento es una respuesta con raíces cristianas a la naturalización de castas que se produce entre los ricos, quienes sienten amenazada su pureza con el contacto con los otros. Estos otros responden con resentimiento, que a veces se traslada hacia la lucha de clases, pero es un tránsito complejo e inestable, pues supone un tránsito desde la inmovilidad a una movilización.

c) La relación 'aspiracional', con un fuerte proceso de identificación de los grupos más bajos sobre los altos. Opera por varios procedimientos. Por un lado, la identificación con la ya mencionada 'ética del emprendimiento' donde se internaliza la idea de que se puede ser algo cercano a un empresario desde cualquier posición en la estructura social. Esta visión es incipiente. Más consolidada se encuentra la aspiracionalidad por vía del consumo, con escasos niveles de racionalización de la imagen de mundo y basada en la experiencia emocional de satisfacción que da la compra, la que permite aproximarse a las sensaciones y conductas propias de los grupos más altos.

Este tipo de relaciones parece encontrar un fértil terreno simbólico en la mirada sobre lo merecido de las situaciones de pobreza y riqueza. Este marco valorativo, por su aparente importancia cualitativa, fue medido en una encuesta el año 2005, con sorprendentes resultados. El siguiente cuadro muestra los resultados de tres preguntas relacionadas con los marcos valorativos que permiten internalizar las diferencias en ingreso y la visión de la posición de los trabajadores en el mundo laboral.

\section{Mérito o Injusticia de la Riqueza de los Ricos}

\begin{tabular}{l}
$\begin{array}{l}\text { La riqueza tiene su origen en el mérito de quien la ha } \\
\text { conseguido }\end{array}$ \\
\hline $\begin{array}{l}\text { La riqueza proviene de injusticias cometidas por quienes } \\
\text { la han conseguido }\end{array}$ \\
$\begin{array}{l}\text { Visión sobre lo Contradictorio o Armónico de los Intereses de los } \\
\text { Empresarios respecto a los Trabajadores }\end{array}$
\end{tabular}

En general, lo que es conveniente para el empresario perjudica al trabajador

$48,4 \%$

En general, los intereses de los trabajadores y de los empresarios están en sintonía, por lo que el beneficio de uno es también del otro. 


\section{Explotación de los Trabajadores}

Mayoría de los Trabajadores + Muchos de los trabajadores son explotados por quienes los contratan

Sólo algunos trabajadores son + Casi ningún Trabajador son explotados por quienes los contratan

$$
70,6 \%
$$

$29,4 \%$

Fuente: Encuesta Expert-Centro de Estudios Sociales y Políticos, 2006, ciudad de Santiago.

Estas valoraciones han demostrado tener implicaciones relevantes a nivel de, por ejemplo, conductas electorales. Esto es, la construcción de sentido sobre las diferencias sociales se asocia a la dimensión de la acción social y ello se puede apreciar en el espacio político con mucha claridad. Como fue expresado en un artículo anterior (Mayol, 2005), la legitimación o no de la riqueza es de alta importancia como eje explicativo de conductas electorales. El siguiente gráfico es muy claro al respecto.

\section{GRÁFICO 2}

\section{Diferencias de Preferencia Electoral según Actitud sobre la Legitimidad del Origen de la Riqueza y según Nivel Socioeconómico}

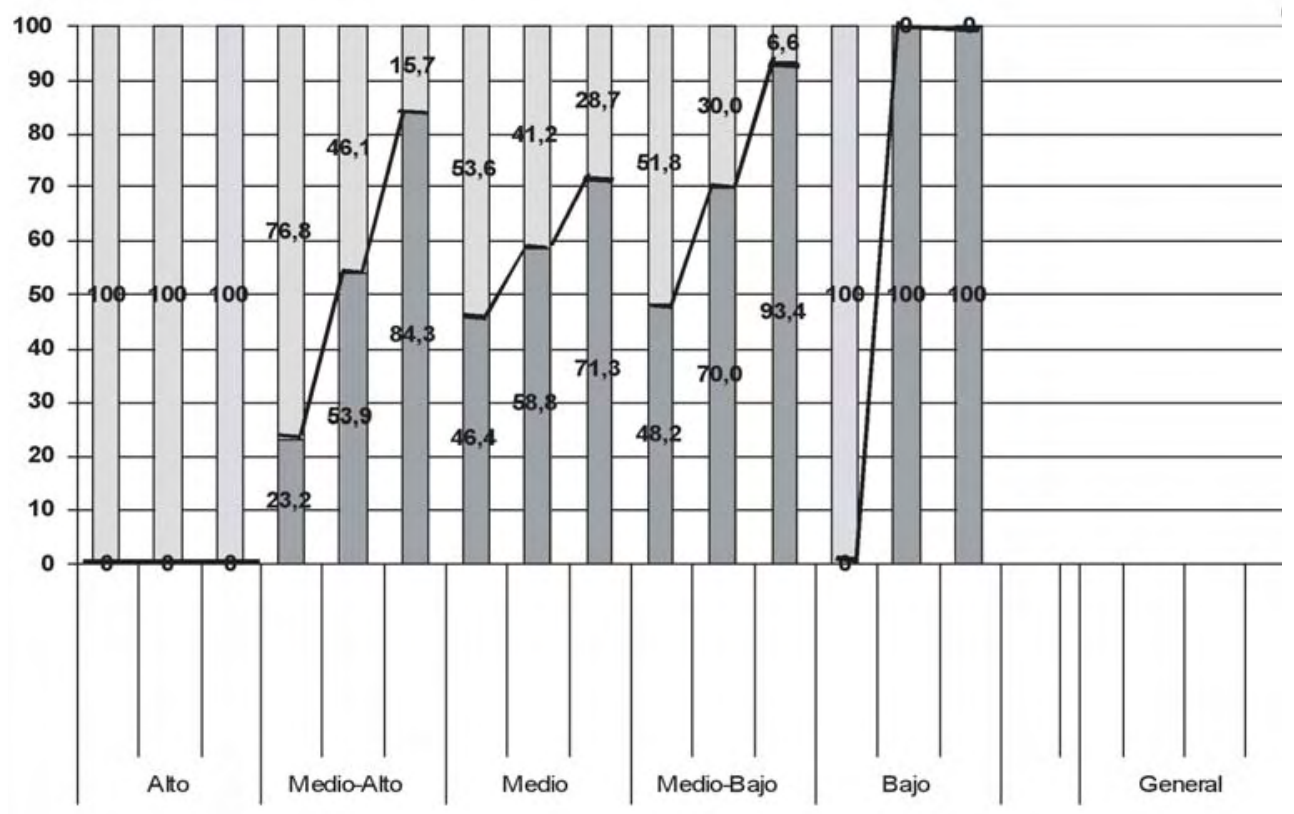

NOTA: Se excluyen los electores no definidos.

FUENTE: Encuesta Expert-Centro de Estudios Sociales y Políticos, 2005, ciudad de Santiago.

“Apreciamos en el gráfico que, salvo en el grupo socioeconómico más alto (donde sin excepción e independiente de la preferencia electoral, siempre se considera la 
Memorias del Subsuelo: Exploración de la Economía de los Valores en el Chile Actual / Alberto Mayol Miranda

riqueza proveniente del mérito), en todos los demás niveles socioeconómicos la probabilidad de votar por la Alianza está fuertemente asociada a considerar al mérito como padre de la riqueza. En el nivel socioeconómico más bajo apreciamos radicalmente esta situación: si se cree en el mérito para llegar a la riqueza, la conducta electoral, la votación, sólo será por la Alianza; si se cree en la injusticia como fuente de la riqueza, la conducta electoral se mueve restrictivamente entre dos opciones, la Concertación y el Juntos Podemos, excluyendo totalmente a la Alianza. De este modo, la lucha de clases es una fuente de sentido político mucho más intensa que la mera posición en la escala de ingreso económico de la sociedad. Las diferencias entre las coaliciones políticas son marcadas por nivel socioeconómico, pero lo son aún más si al nivel socioeconómico le agregamos la cuestión del mérito o injusticia de la riqueza" (Mayol, 2005: 109 y 110).

Este ejemplo ilustra cómo a partir de la observación de la economía de los valores de una sociedad es posible vincular cuestiones estructurales con la dimensión de los actores sociales. He aquí un desafio fundamental para el trabajo en la investigación cultural, cuyo mérito ha de estar en la comprensión del movimiento de las formas del imaginario socialmente construido. Como se aprecia, hay distinciones sociales (en términos de clase o estamentos) que se despliegan en forma política; al tiempo que son también las formas políticas las que adquieren formulaciones en el ethos o en el pathos. El principio fundamental de todo análisis cultural, esto es, el que hay una indeterminación de base en las formas simbólicas (Cassirer, 1998) y que la conquista de la forma es un proceso social que no vence nunca por completo esta indeterminación, supone a los investigadores un desafio enorme en términos de la producción y validación del conocimiento en la dimensión cultural. A este respecto, la comprensión de los marcos valorativos del Chile actual constituye un esfuerzo por comprender la textura de un mundo simbólico que parece combinar necesidades despolitizadoras de orden, transformaciones relevantes en la esfera de la ética económica (emprendimiento y consumo) y fracturas culturales de alta importancia a la hora de observar la sociedad desde las distintas posiciones sociales, particularmente dada la distancia ya no sólo objetiva (económica), sino también subjetiva (cultural) que está en creciente consolidación.

El presente artículo no ha tenido más pretensión que la de articular descripciones conocidas respecto al caso chileno con nuevos materiales, además de abrir nuevas oportunidades interpretativas que puedan resultar de relevancia. El ya mencionado ejercicio de collage ha otorgado ciertas oportunidades irresponsables de las que ya no vale la pena arrepentirse. 
Revista de Sociolocía 21 / 2007 Chile Hoy

Facultad de Ciencias Sociales - Universidad de Chile

\section{Bibliografía}

BAÑO, Rodrigo (1992): De Augustus a Patricios. Santiago: Editorial Amerinda.

CAMARGO, Ricardo (s/f): "El Carácter Traumático del Consenso en torno al 'Modelo Chileno': Una Investigación sobre la Elite Política Democrática Post-Pinochet", en Nuevo Mundo Mundos Nuevos, disponible desde 2008 en el Número 8 de la revista. Dirección web: http://nuevomundo.revues.org

CEP (2007): Estudio Nacional de Opinión Pública N 56. Noviembre-diciembre 2007. Dirección web: http://www.cepchile.cl/

CASSIRER, Ernst (1998): Filosofia de las Formas Simbólicas, Tomo 3. México: Fondo de Cultura Económica.

CORTÉS, Antonio (s/f): "Calidad de Vida en Chile: reflexiones críticas sobre las mediciones" en Revista Perspectivas (Departamento de Ingeniería Industrial, Universidad de Chile), vol. 5, No 1, 2001 (pp. 89-101)

http://www.dii.uchile.cl/ revista/ArticulosVol5-N1/07-A.sep.pdf

FINOL, José Enrique (2006): “Globalización y cultura: estrategias simbólicas y vida cotidiana” en Revista de Ciencias Sociales, v. XII, No. 3, Septiembre - Diciembre 2006, pp. 454-475. Universidad del Zulia (Maracaibo,Venezuela).

HABERMAS, Jürgen (1999); Teoría de la Acción Comunicativa, I: racionalidad de la acción y racionalización social. Madrid: Editorial Taurus.

INGLEHART, Ronald (1994): “Modernización y Post-Modernización: la cambiante relación entre el desarrollo económico, cambio cultural y político" en DÍEZ NICOLÁS, Juan e INGLEHART, Ronald (eds): Tendencias Mundiales de Cambio en los Valores Sociales y Politicos. Madrid: Ediciones de Fundesco.

KLUCKHON, Clyde (1951): "Values and Value-Orientations in the Theory of Action", en PARSONS, Talcott y SHILS, Edward: Toward a General Theory of Action, Cambridge:Harvard University Press.

LAHERA, Eugenio (s/f): “¿Qué está pasando en Chile?” en Revista Nueva sociedad No 197 http://www.nuso.org/upload/articulos/3260_1.pdf

LARRAÍN, Jorge (2001): Identidad Chilena. Santiago: Lom Editores.

LARROULET, Cristián (1984): "Reflexiones en Torno al Estado Empresario en Chile" en Documento de Trabajo del Centro de Estudios Públicos, №22. 
Memorias del Subsuelo: Exploración de la Economía de los Valores en el Chile Actual / Alberto Mayol Miranda

MAYOL, Alberto (2006): “Heráclito y Parménides en el Chile del 2005: crónica de las trizaduras y persistencias de los grandes relatos” en Revista Análisis del Año 2005. Santiago: Universidad de Chile. Dirección URL: http://www.facso.uchile.cl/publicaciones/sociologia/docs/analisis2005.pdf.

MAYOL, Alberto (2007): "De Pinochet a Bachelet: los ejes culturales de la dominación de 1973 a 2006” en Revista Análisis del Año 2006. Santiago: Universidad de Chile. Dirección URL: http://www.facso.uchile.cl/publicaciones/sociologia/docs/ analisis2006.pdf.

MONTECINOS,Verónica; “ElValor Simbólico de los Economistas en la Democratización de la Política Chilena" en Revista Nueva Sociedad Número 152, Edición de Noviembre-Diciembre de 1997, Caracas, Venezuela. URL: http://www.nuso.org/ upload/articulos/2643 1.pdf

MOULIAN,Tomás (2002) Chile Actual:Anatomía de un Mito. Santiago: LOM Editores.

PARSONS, Talcott (1974): El Sistema de las Sociedades Modernas. México D.F.: Ediciones Trillas.

PARSONS, Talcott (1982): El Sistema Social. Madrid: Alianza Editorial.

PIAGET, Jean (1983): Estudios Sociológicos. Barcelona:Ariel.

PNUD (1998): Desarrollo Humano en Chile 1998. Las Paradojas de la Modernización. Santiago.

RICHARDS, Nelly (2007): Fracturas de la Memoria. Buenos Aires: Siglo XXI Editores.

RICOEUR, Paul (2003): El Conflicto de las Interpretaciones. Ensayos de hermenéutica. Buenos Aires: Fondo de Cultura Económica.

SIMMEL, Georg (2001): El Individuo y la Libertad. Ensayos de crítica de la cultura. Barcelona: Península.

SILVA, Patricio; “Ascenso Tecnocrático y Democracia en América Latina” en Revista Nueva Sociedad Número 152, Edición de Noviembre-Diciembre de 1997, Caracas, Venezuela.

SOROKIN, Pitirim (1969): Sociedad, Cultura y Personalidad. Madrid:Aguilar.

THAYER, Willy (2006): El Fragmento Repetido. Escritos en Estado de Excepción. Santiago: Metales Pesados.

TIRONI, Eugenio (1999) La Irrupción de las Masas y el Malestar de las Elites: Chile en el cambio de siglo. Santiago: Grijalbo. 
ReVista de Sociología 21 / 2007 Chile Hoy

Facultad de Ciencias Sociales - Universidad de Chile

TÖNNIES, Ferdinand (1987): Principios de Sociología. México: Fondo de Cultura Económica.

VALENZUELA, Iván (2005): “Cultura y economía: La encrucijada de los valores en el desarrollo.” Ciencias Sociales Online, Septiembre 2005,Vol. II, No. 2 (49-64). URL: http://www.uvm.cl/csonline/2005_2/pdf/cultura_economia.PDF.2

WEBER, Max (1996): Economía y Sociedad. México: Fondo de Cultura Económica.

WEBER, Max (1998): Ensayos sobre Sociología de la Religión I. Madrid:Taurus.

WEBER, Max (2004): El Político y el Científico. Madrid:Alianza. 